\title{
Relationship between ATSR fire counts and CO vertical column densities retrieved from SCIAMACHY onboard ENVISAT
}

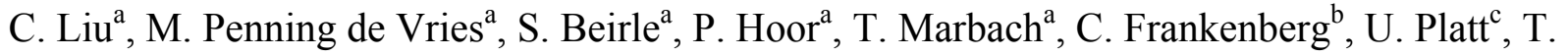 \\ Wagner $^{\mathrm{a}}$ \\ ${ }^{a}$ MPI for Chemistry, Mainz,Germany,; \\ ${ }^{\mathrm{b}}$ SRON, Netherlands Institute for Space Research, Earth Oriented Science Division, The Netherlands \\ 'Institute for Environmental Physics, University of Heidelberg, Germany \\ Email: liucheng@mpch-mainz.mpg.de.Tel: Tel: +49 (0) 6131305364
}

\begin{abstract}
SCIAMACHY (Scanning Imaging Absorption spectroMeter for Atmospheric ChartographY) is the first instrument to allow retrieval of $\mathrm{CO}$ by measuring absorption in the near infrared from reflected and scattered sunlight instead of from thermal emission. Thus, in contrast to thermal-infrared satellites (MOPITT), SCIAMACHY is highly sensitive to the lower layers of the troposphere where the sources, such as biomass burning, are located, and where the bulk of the CO is usually found.

In many regions of the world, the burning of vegetation has a repeating seasonal pattern, but the amount of $\mathrm{CO}$ emitted from biomass burning varies considerably from place to place. Here we present a study on the relationship between fire counts and $\mathrm{CO}$ vertical column densities (VCD) in different regions. These results are compared with the CO VCD from MOPITT, aerosol index, and $\mathrm{NO}_{2}$ tropospheric VCD (TVCD) from SCIAMACHY, and the coupled chemistry climate model (CCM) ECHAM5/MESSY.
\end{abstract}

Keywords: fire count, biomass burning, $\mathrm{CO}$, aerosol index, $\mathrm{NO}_{2}$ TVCD, SCIAMACHY

\section{INTRODUCTION}

Public awareness of the environmental impacts of biomass fires and justified concern about its consequences are growing, since biomass burning serves a variety of purposes: the clearing of forests for agricultural use, energy production for cooking and heating, control of pests, insects and weeds, or nutrient mobilization ${ }^{[1]}$.

Biomass fires cause significant regional pollution, often with severe impacts on the health and safety of the local population. On a global scale, it affects atmospheric chemistry and climate, as it produces a cocktail of ozone precursors, e.g. $\mathrm{CO}, \mathrm{NO}_{\mathrm{X}}$ and aerosols ${ }^{[2]}$.

The input of biomass burning emissions into the atmosphere is often discussed as phenomenon of tropical rain forests and savannas ${ }^{[1]}$.Tropical landmasses are exposed to yearly biomass burning, typically with a distinct seasonal cycle. In contrast, the Indonesian fires were due to a disastrous fire event where large amounts of peat were burnt, enabled by drainage of swamp areas and the drought during the incidence of El Niño ${ }^{[3]}$.

The retrieval of $\mathrm{CO}$ from SCIAMACHY is a real challenge: $\mathrm{CO}$ is a relatively weak absorber whose spectral signature is overlapped by strong $\mathrm{CH}_{4}$ and $\mathrm{H}_{2} \mathrm{O}$ absorptions. Also there are some systematic problems with SCIAMACHY's near infrared channel: a) the varying ice layer on the near-infrared detectors, b) the orbital variation of the instrument's dark signals, c) the increase in dead/bad detector pixels ${ }^{[4]}$. Nevertheless it has been shown that reliable results can be obtained $[5,6]$.

Satellite data are of importance to study temporal and spacial patterns on global scale. Comparison with other satellite measurements of atmospheric constituents like trace gases, aerosols, clouds or other observed quantities like fire counts and lighting gives information on sources, and transport processes. The comparison with model data can also help improve the model and understand chemical and physical processes determining the distribution of $\mathrm{CO}$ in the atmosphere, in particular the distribution of sources and sinks.

Remote Sensing of Fire: Science and Application, edited by Wei Min Hao,

Proc. of SPIE Vol. 7089, 70890I, (2008) · 0277-786X/08/\$18 · doi: 10.1117/12.793283

Proc. of SPIE Vol. 7089 70890I-1 
In this paper we study the correlation between fire counts and vertical column density (VCD) of $\mathrm{CO}, \mathrm{NO}_{2}{ }^{[7,8]}$, and the aerosol index in different typical biomass burning regions of the world ${ }^{[9,14]}$. We compare CO VCD from SCIAMACHY and from MOPITT ${ }^{[9]}$ to study e.g. the convective up-lift of $\mathrm{CO}$ which is possible because in contrast to MOPITT, SCIAMACHY is very sensitive to $\mathrm{CO}$ in the boundary layers.

Clouds influence the depth of absorption lines of a trace gas in the spectrum, in particular if the trace gas concentration is high in the troposphere. For the retrieval of tropospheric trace gas columns it is therefore essential to have information on the cloud cover conditions. Both the cloud fraction and the cloud pressure are needed as input for the trace gas retrieval algorithms. For the TEMIS project, the (effective) cloud fraction and cloud pressure are derived from SCIAMACHY measurements with the FRESCO+ cloud algorithm ${ }^{[10]}$. We used those cloud parameters as input for our cloud-filtering procedure.

\section{INSTRUMENT AND DATA SETS}

SCIAMACHY onboard the European Space Agencies environmental research satellite ENVISAT consists of 8 grating spectrometers measuring in the ultraviolet, visible and near infrared wavelength region $(240 \mathrm{~nm}-2380 \mathrm{~nm})^{[11]}$. The satellite operates in a near polar, sun-synchronous orbit at an altitude of $800 \mathrm{~km}$ and a local equator crossing time at approximately 10:00 am. In each orbit, a swath width of $960 \mathrm{~km}$ across track with a usual pixel resolution of $30 \mathrm{~km} \times 60$ $\mathrm{km}$ is covered, which is a substantial improvement to the large footprint of the predecessor instrument GOME onboard ERS-2. Global coverage is achieved every six days. For the CO retrieval, the typical ground pixel size is $30 \mathrm{~km}$ (along track) times $120 \mathrm{~km}$ (across track), whereas for the aerosol index and $\mathrm{NO}_{2}$ retrieval, the ground pixel size is $30 \mathrm{~km} \times 60$ $\mathrm{km}$. We use iterative maximum a posteriori Differential Optical Absorption Spectroscopy (IMAP-DOAS) ${ }^{[12]}$ to retrieve CO. This method directly iterates the vertical column densities of the absorbers of interest until the expected spectral signature of the total optical density fits the measurement. It accounts for nonlinearities due to spectrally unresolved strong absorptions and considers sensitivity to pressure and temperature changes in the atmospheric profile. Here CO VCDs for cloud fraction below 5\% (as determined by FRESCO+, data downloaded from www.temis.nl/fresco) are used.

The MOPITT remote sensing instrument, which was developed to quantify and track the movement of pollution in the troposphere, was launched aboard the EOS Terra satellite in December, 1999. Global distributions of CO are measured by the MOPITT thermal infrared channel with $22 \mathrm{~km} \times 22 \mathrm{~km}$ horizontal resolution using forward model ${ }^{[13]}$. It should be mentioned here that the MOPITT CO VCD was calculated using constant a priori data.

The fire counts data set that we use is from the ATSR sensor on board the ERS-2 satellite ${ }^{[14]}$. This data set is the only one with global coverage that is available for a reasonably long time period. For the ATSR fire product, only nighttime observations are used, and a threshold of $312 \mathrm{~K}$ (algorithm 1) or 308K (algorithm 2) is applied to the radiance of the $3.7 \mu \mathrm{m}$ channel in order to detect fires. In our study we use algorithm 2 . The resolution of the ATSR sensor is $1 \times 1 \mathrm{~km}^{2}$, which allows for detection of a $600 \mathrm{~K}$ hot spot of 0.1 ha or an $800 \mathrm{~K}$ hot spot of 0.01 ha. The sensor achieves complete global coverage every three days.

UV aerosol indices are calculated from the residue, a quantity that indicates the contrast of a satellite ground pixel at two wavelengths in the UV ${ }^{[7]}$. It is calculated by comparing the radiance of a measured scene at two wavelengths in the UV (in our case: 335.5 and $376.5 \mathrm{~nm}$ ) with the radiances calculated by assuming a pure Rayleigh atmosphere bounded by a Lambertian reflector with a certain surface albedo. The surface albedo is determined by the measured radiance at 376.5 $\mathrm{nm}$. Depending on the sign of the residue, the aerosol indices are referred to as AAI (Absorbing Aerosol Index, positive residue) or SAI (Scattering Aerosol Index, negative residue) ${ }^{[15]}$. High AAI values may be caused by the presence of UV absorbing aerosols, such as biomass burning aerosols or desert dust, especially if the aerosol layer resides at large altitude. High SAI values are found for scenes with low-lying layers of moderately absorbing aerosols or scattering aerosols (e.g. sulfate droplets).

The aerosol indices were calculated as described in ${ }^{[15]}$. To correct for the degradation in the UV channel, a timedependent offset was subtracted ${ }^{[16]}$, and an additional constant offset was added to the data to correct for errors in the absolute radiances measured by SCIAMACHY. Only data from pixels with effective cloud fractions smaller than 5\% (as determined by FRESCO+) was plotted; no further cloud corrections were applied. 
$\mathrm{NO}_{2}$ column densities are retrieved from SCIAMACHY measurements in the blue spectral range (430-450 nm). Tropospheric columns are derived by subtracting the stratospheric column that is estimated over the remote Pacific and assumed to be zonally constant ${ }^{[17]}$. The resulting tropospheric slant column densities (TSCDs) are converted into tropospheric vertical column densities (TVCDs) using box Air Mass Factors (AMFs) calculated by the Monte Carlo Radiative Transfer Model McArtim, an advancement of TRACY II ${ }^{[18]}$. The box AMFs are calculated (a) for different Solar Zenith Angle (SZA), (b) for cloud free as well as clouded scenes for various Cloud Top Height (CTH), and (c) for different ground level heights, and are stored in a look-up table. A ground albedo of $5 \%$ was assumed. Every TSCD is then converted into a TVCD with the appropriate box-AMF, accounting for the actual SZA, Cloud Fraction (CF), and $\mathrm{CTH}$ (taken from FRESCO +). For the conversion, we assume a $\mathrm{NO}_{2}$ profile with a constant concentration in the boundary layers ( $1 \mathrm{~km}$ high), containing $80 \%$ of the total column, and constant mixing ratio from 1 to $15 \mathrm{~km}$, containing the remaining $20 \%$. The resulting column densities are gridded to global maps with $0.5^{\circ}$ resolution. Monthly averages are calculated for cloud fraction thresholds of $5 \%$.

The model data which are used in this study are based on the evaluation simulation of ECHAM5/MESSy covering the period from 1998-2005 ${ }^{[19]}$. For this simulation the model was run with a spectral resolution of T42 (approx. $2.8 \times 2.8$ degrees) with 90 vertical levels spanning from the surface to $0.01 \mathrm{hPa}$ resolving the troposphere with approximately 28 levels. The model was nudged to ECMWF operational data in the troposphere up to $200 \mathrm{hPa}$, which allows comparisons with real atmospheric measurements. The chemical mechanism includes 104 gas phase species and 245 reactions covering the troposphere and the stratosphere resulting in a self-consistent simulation from the surface to the mesosphere. The chemical boundary condition was based on the EDGAR3.2FT2000 emission inventory ${ }^{[20]}$, and included monthly resolved biomass burning emissions for the year 2000, which were applied to the whole simulation period.

\section{RESULTS}

The gas and particle emission characteristics of biomass fires vary from place to place due to different vegetation types or weather conditions. It is instructive to analyze correlations between atmospheric constituents and fire counts for different areas. In the following, we computed correlations and time series of monthly means of fire activity from ATSR, CO VCD from SCIAMACHY, MOPITT and Model, $\mathrm{NO}_{2}$ TVCD and aerosol index for some of regions indicated with boxes in Fig.1: (a) northern Africa, (b) Central Africa(East), (c) Central Africa (West), (d) Central South America, (e) Northern Australia, (f) Southern Asia, (g) Indonesia, (h) Alaska, (i) Russia 1, and (j) Russia 2. In Fig. 1 also fire counts for 2004 are shown.
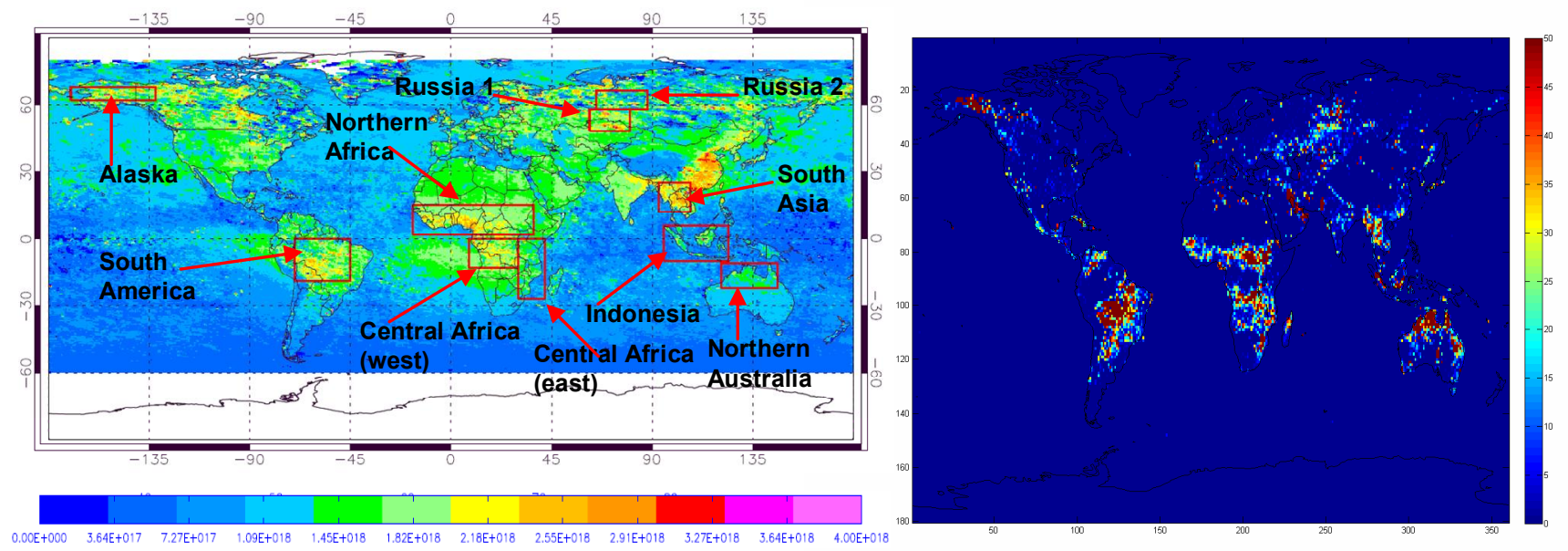

Fig. 1. Left: The yearly mean CO VCD retrieved from SCIAMACHY 2004 (Units: molec/cm²). The boxes mark regions of high biomass burning activity that are considered in detail below. Right: Global fire frequency (Units: fire counts per pixel $\left(1^{\circ} \times 1^{\circ}\right)$ per month) as seen by ATSR in 2004.

Since the life time of $\mathrm{CO}$ is relatively long and SCIAMACHY needs 3 days to reach global coverage, we chose to analyze monthly correlations between fire counts and the VCD of trace gases. Fig. 2 shows the yearly cycles (monthly means) of fire counts and $\mathrm{CO} \mathrm{VCD}, \mathrm{NO}_{2} \mathrm{TVCD}$ and aerosol index for these regions. The different years are color coded, 
black for 2004 and red for 2005, to allow a direct comparison of single years. The aerosol index is shown only for 2005 due to sensor anomalies during June and August 2004.

Please note that the absolute scale of each kind of plots is the same except Alaska and Russia 2: there, extremely high fire counts per $\mathrm{km}^{2}$ per month are found.

(a) Northern Africa
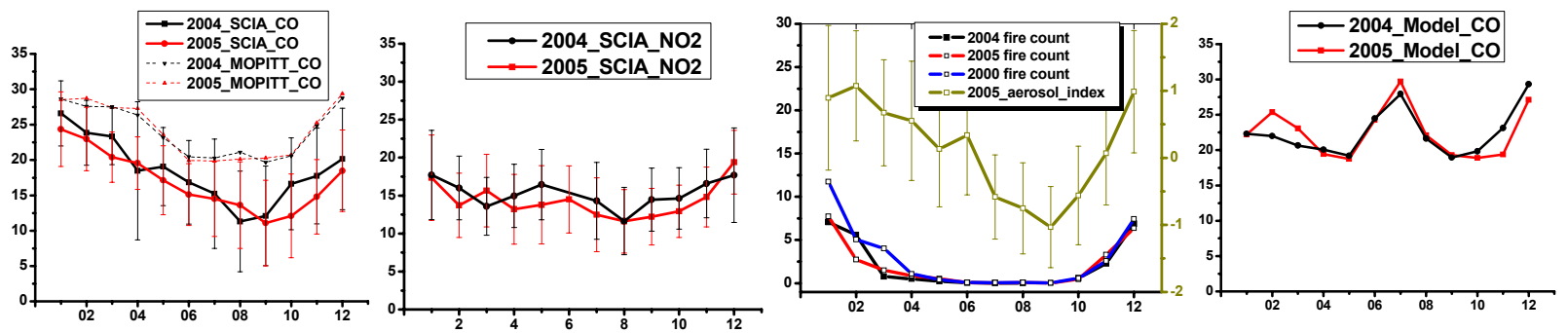

(b) Central Africa(East)
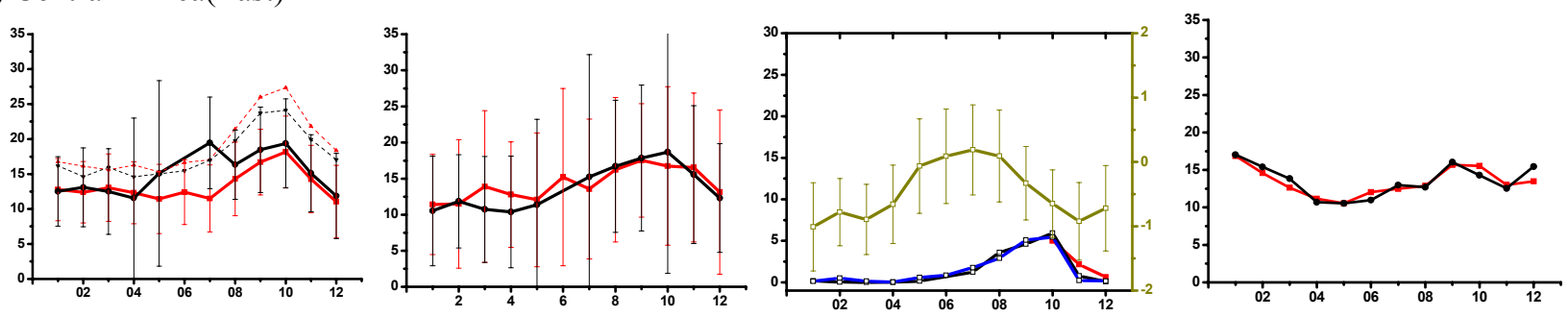

(c) Central Africa( West)
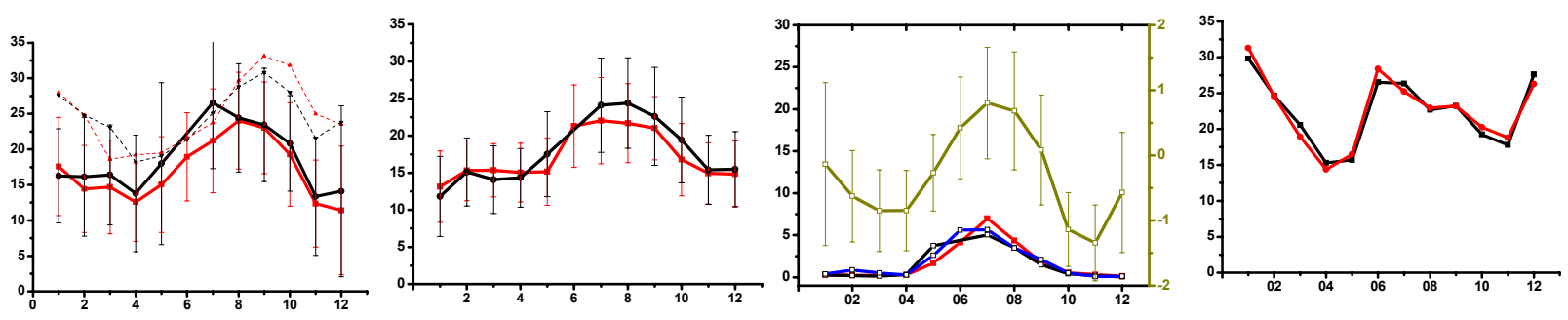

(d) Central South America
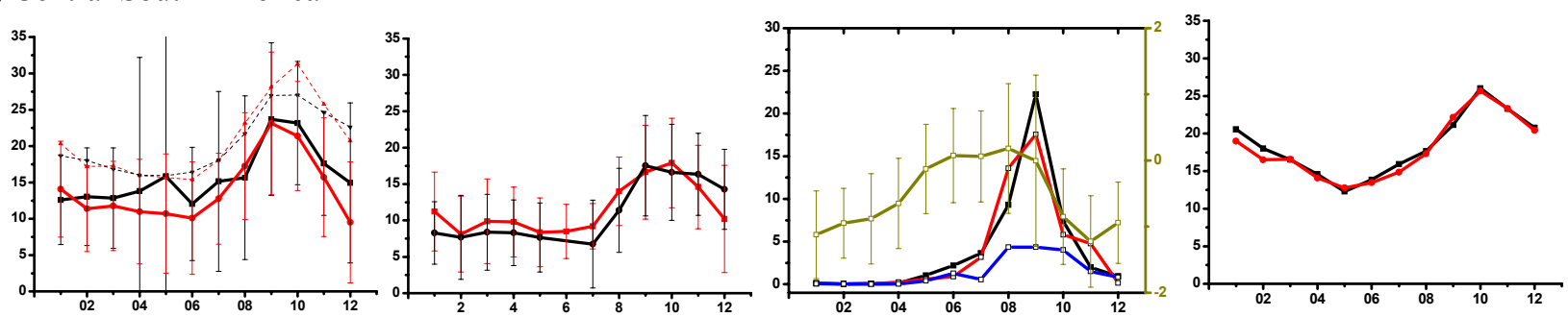

(e) Northern Australia
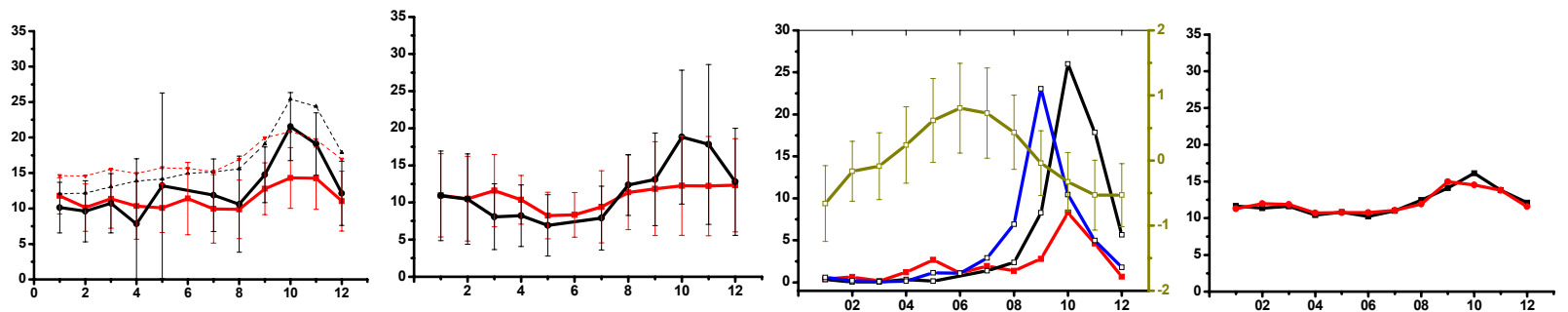
(f) Southern Asia
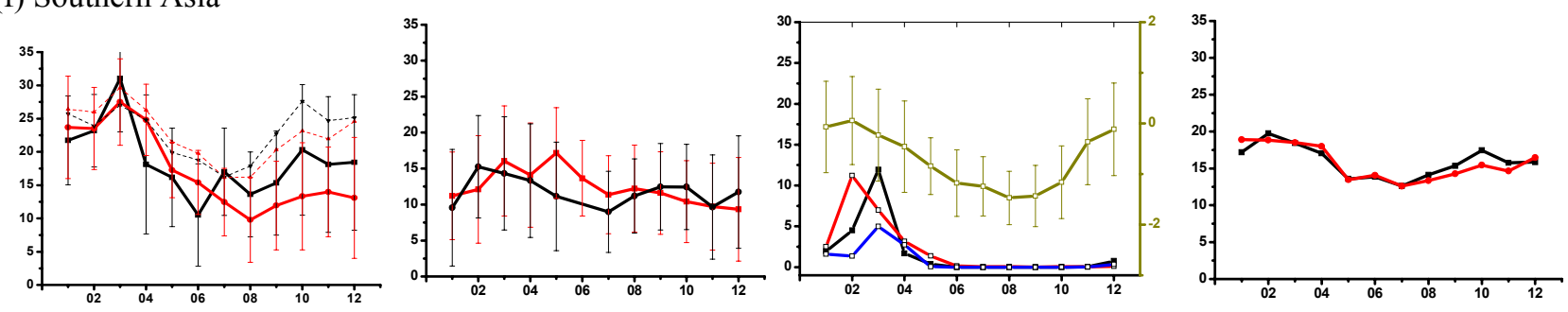

(g) Indonesia
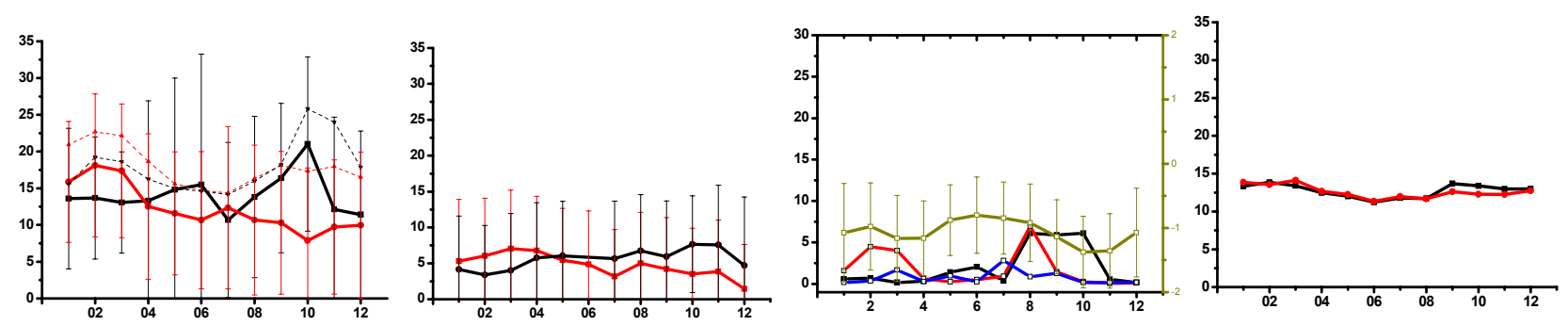

(h) Alaska
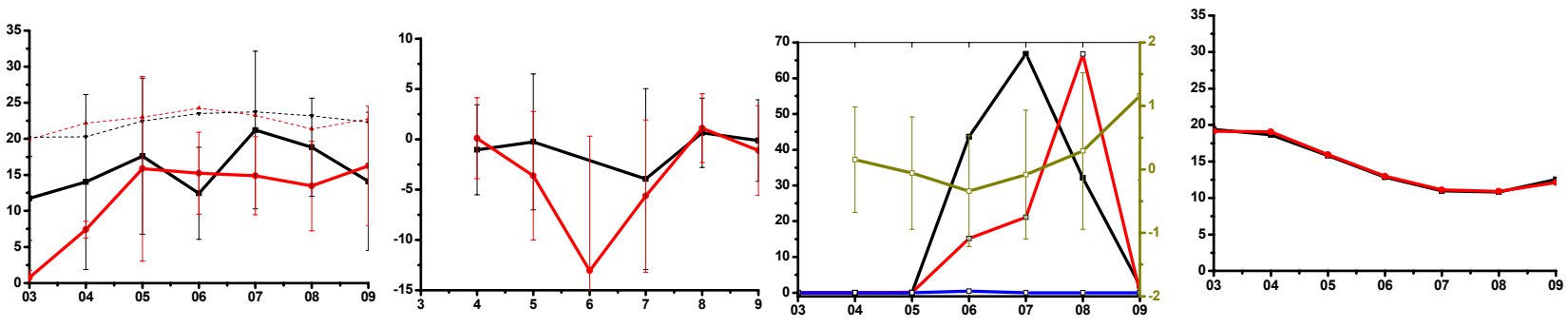

(I) Russia 1
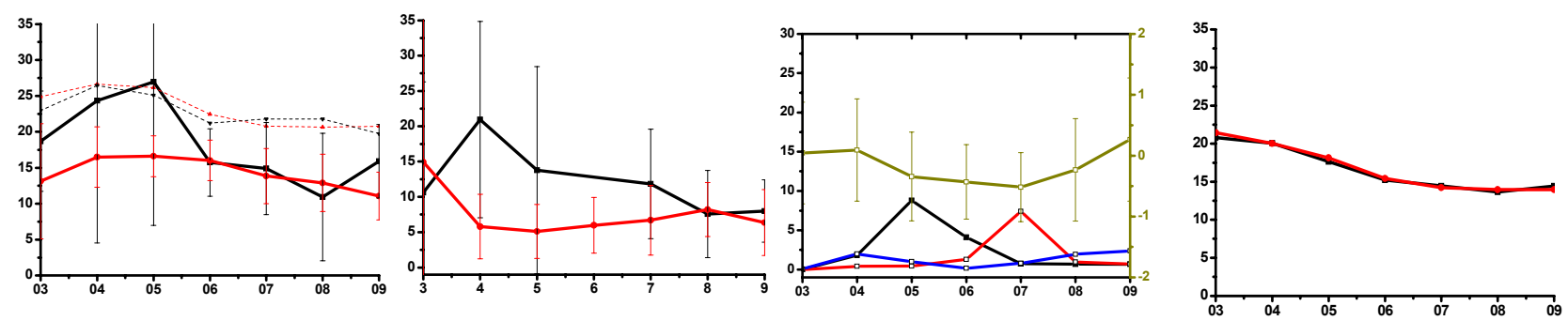

(j) Russia 2
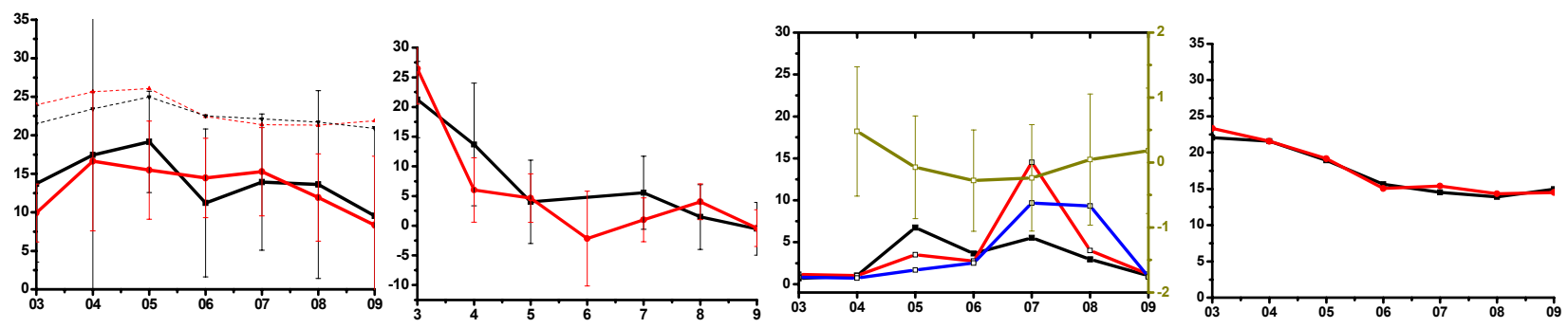
Fig. 2. Time series of monthly means of fire counts from ATSR, CO VCD from SCIAMACHY, MOPITT, and ECHAM5/MESSy; $\mathrm{NO}_{2}$ TVCD and aerosol index from SCIAMACHY for the regions as indicated in Fig.1 The different years are color coded (see legend). Aerosol index is shown only for 2005 (see text). The unit of ATSR fire counts is $10^{-4}$ per $\mathrm{km}^{2}$ per month. The blue curve refers to the year 2000 , on which the model biomass burning emissions are based. The unit of CO VCD and $\mathrm{NO}_{2}$ TVCD are $10^{17} \mathrm{molec} / \mathrm{cm}^{2}$ and $10^{14} \mathrm{molec} / \mathrm{cm}^{2}$ respectively. The error bars for SCIAMACHY CO, $\mathrm{NO}_{2}$, and aerosol index indicate the standard deviation of the monthly averages.

For most regions, the correlation between fire counts and experimental data $\left(\mathrm{CO}, \mathrm{NO}_{2}\right.$ and aerosol index from SCIAMACHY, CO from MOPITT) is good, except for the three northern regions (Alaska, Russia 1 and Russia 2).See Fig. 3. Besides possibly smaller atmospheric signals at these regions, also the measurement sensitivity is reduced there because of larger solar zenith angles (especially during winter). There are several additional reasons for deviations from perfect correlation: measurement errors (e.g. due to small number of cloud-free pixels), but also meteorological circumstances (transport in or out of the region of study), the presence of additional sources, or saturation effects (i.e., for a high number of fires, additional fires do not lead to higher concentrations of certain trace gases). For the relation between fire counts and model CO in general good correlations are found in the southern hemisphere and in the tropics, but somewhat weaker correlations over central Africa. The deviations in high northern latitudes are largely driven by the inter-annual variability of the biomass burning emissions in these regions. As shown in Figure 2) h) during 2000 almost no fire counts were observed (in contrast to 2004 and 2005), resulting in the typical high latitude CO background evolution as simulated by the model.

In Central Africa (West), we found that the maximum of $\mathrm{CO}$ is shifted by one month between SCIAMACHY and MOPITT. This may be related to the combined effect of vertical transport and reduced measurement sensitivity of MOPITT for the boundary layer. There is, however, a systematic offset between SCIAMACHY CO and MOPITT CO, which is most probably caused by instrumental problems (mainly due to the ice deposit on the SCIAMACHY near infrared channels). For northern Africa the temporal evolution of the simulated $\mathrm{CO}$ columns strongly deviates from the observations for 2004/2005 and is also decoupled from the fire counts for 2000. Given the spatial distribution of the fire emissions in 2000 (not shown) which is similar to the distribution of the fires in 2004/2005, most likely the interplay between fire locations and simulated convection associated with the inter-tropical convergence zone (ITCZ) causes the large differences. The location of the ITCZ and its representation in the model may play a crucial role in particular when considering the separation between northern and central Africa in Figure 1, which might introduce some differences in the model due to the limited horizontal resolution. Note that the correlation between fire counts and simulated CO column is relatively high over tropical South America, where the same processes can be expected to distribute the biomass burning plumes, but which is represented as one 'test' region in this study. A simulation with more realistic fire locations based on the fire statistics of 2004 and 2005 will allow furthering investigation of the observed differences. The agreement between fire counts and aerosol index is very good for Northern Africa and Central Africa (west). Central Africa (east) is an interesting case: the aerosol index hardly correlates with fire counts from this region, but strongly correlates with fire counts of the neighboring Central Africa (west). This implies transport of biomass burning aerosols from west to east, which is somewhat surprising since the dominating wind direction is from east to west. There are, however, several factors influencing the aerosol index: not only the aerosol optical properties (single scattering albedo, optical thickness), but also height of the aerosol layer ${ }^{[7,15]}$. A change in any or a combination of these parameters, which may be due to differences in fuel type (e.g. grass or trees) or weather conditions, can cause a large change in aerosol index.

The aerosol indices for South America and for Southeast Asia both agree partly with the fire counts in those regions: there is a clear peak in the aerosol index seasonal dependence at the maximum fire count. But in both regions, the aerosol index is also high at times when the fire count is small or even zero (May-July in South America; November-December in Southeast Asia). This might be due to transport, but needs more investigation.

In Indonesia in 2004, the maximum CO appears both in SCIAMACHY and MOPITT CO VCD in October although the fires begin to burn in August. This could be explained as an accumulation effect due to the long life time of CO. In 2005, no significant seasonal trend can be distinguished for $\mathrm{NO}_{2}$, or for the aerosol index. 
In Australia, the aerosol index shows a near anti-correlation with fire counts. This is unexpected and needs to be investigated in more detail.

For $\mathrm{NO}_{2}$ TVCDs, generally, we find the same trend as for $\mathrm{CO}$ and fire counts and good correlations. But in Alaska, Russia 1 and Russia 2, the correlations are not good. In addition to the reasons discussed for SCIAMACHY CO VCD, there are two additional reasons for this. One is the assumption of a zonally constant stratospheric $\mathrm{NO}_{2}$ column: this works for low and mid latitudes, but might fail at high latitudes due to the polar vortex. As a consequence, TVCDs can even get negative, and this is the main source for the misssing correlation in Alaska. The other error source could be snow/ice cover for high latitudes. In the spatial patterns of monthly mean $\mathrm{NO}_{2}$ columns, however, a signature of local biomass burning sources can clearly be seen, also for Alaska and Russia.

To obtain a fair comparison with $\mathrm{CO}$ data (both measured and modeled), average $\mathrm{NO}_{2}$ TVCDs and aerosol indices were computed with the same threshold value for the effective cloud fraction of $5 \%$ as CO VCD from SCIAMACHY. No such screening was possible for the fire counts. Re-computing the $\mathrm{NO}_{2}$ and aerosol index data with cloud fractions up to $30 \%$ or up to $100 \%$ (aerosol index only) showed that there is no strong dependence on cloud cover, since the monthly averages were hardly affected by including pixels with larger cloud fractions (data not shown).

We use the time series also to determine correlation coefficients between fire counts and CO VCD (from SCIAMACHY, MOPITT as well as model data), $\mathrm{NO}_{2}$ TVCD, and aerosol index. The results are shown in Fig 3.

(a)

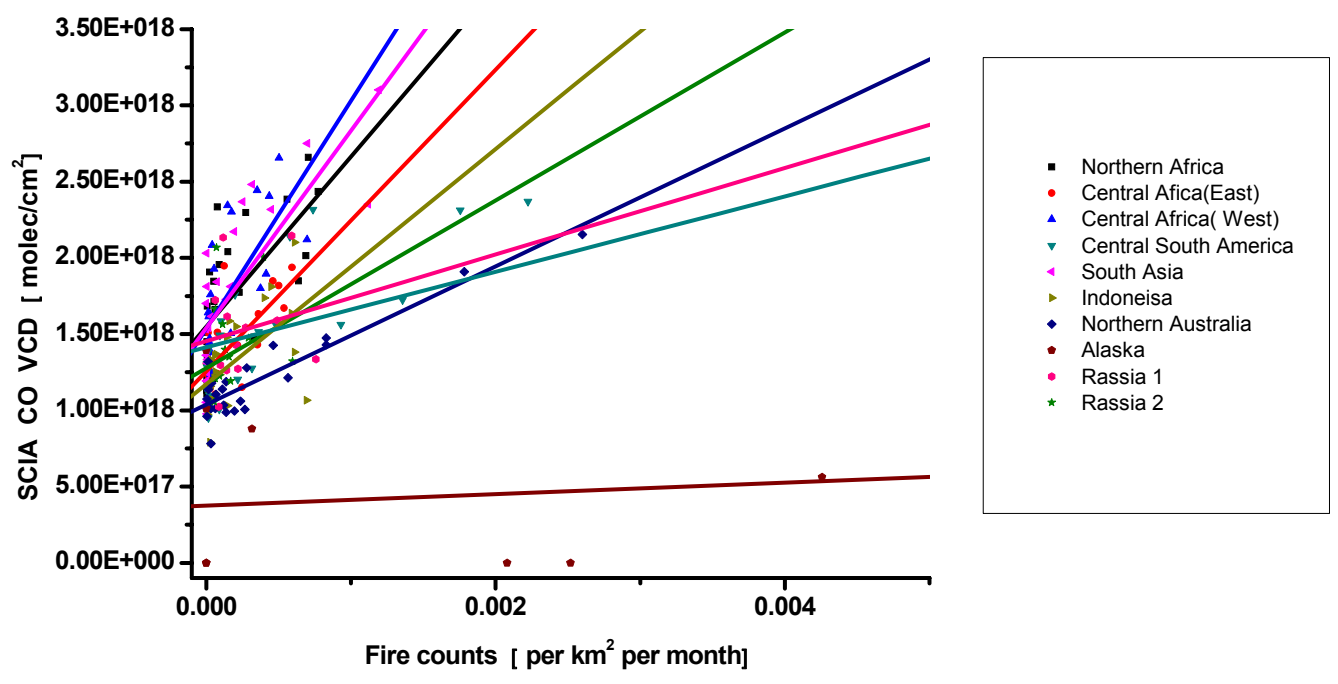

(b)

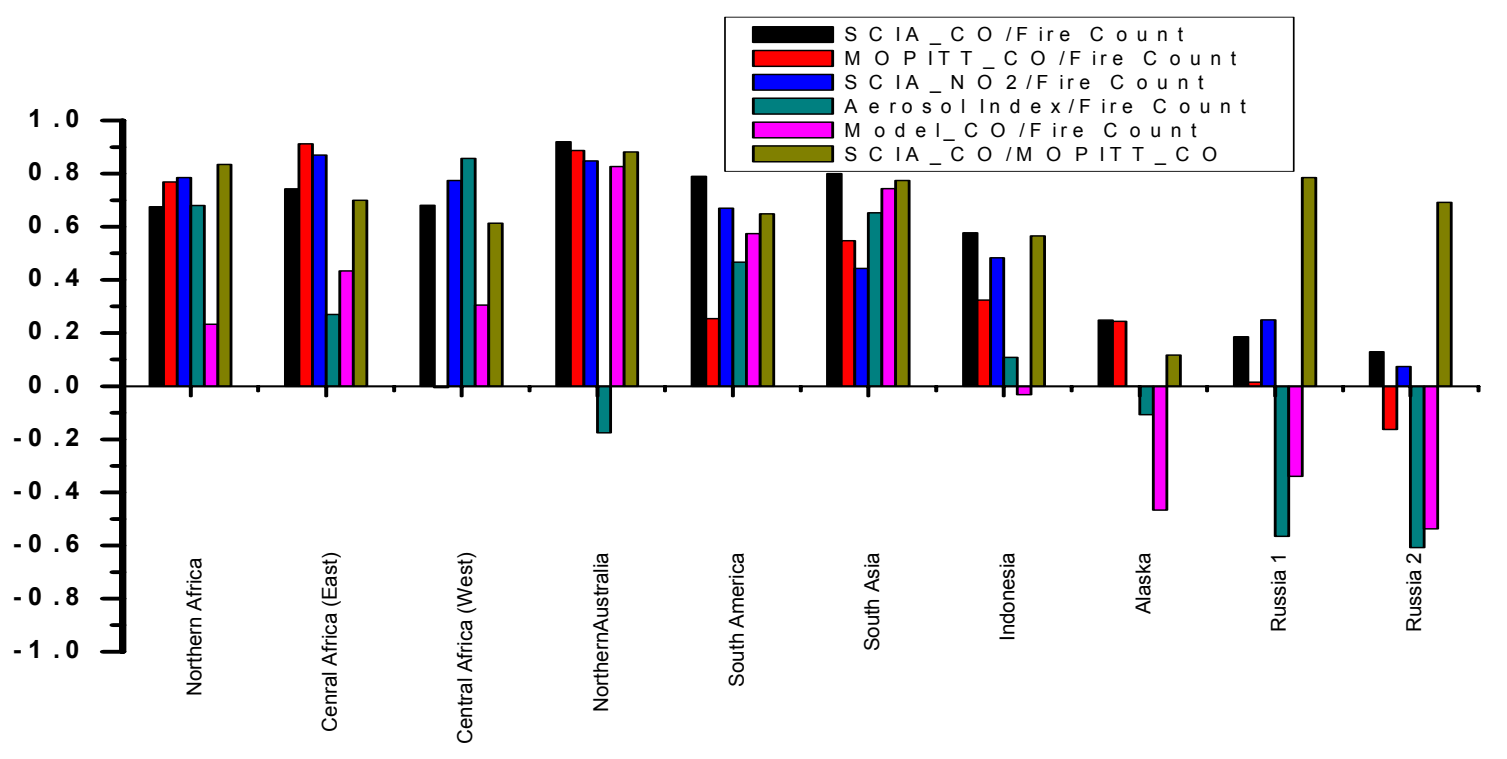


Fig.3 (a) Correlation between fire counts and SCIAMACHY CO VCD for regions under consideration, linear fits (solid lines) were performed for each region separately.

(b) Correlation coefficient for fire counts with $\mathrm{CO} V \mathrm{VD}, \mathrm{NO}_{2} \mathrm{TVCD}$, and aerosol index for regions under consideration. The correlation of CO VCDs from SCIAMACHY and MOPITT is also shown. Note that the biomass burning in the model is represented by the emissions of the year 2000 .

In Fig. 3 (a) we show scatter-plots of SCIAMACHY CO versus fire counts for the different regions with linear fits. The slope of these linear fits can be interpreted as being proportional to the amount of CO produced (or, more accurately: detected) per fire count. In this sense, Fig 3 shows that for fires in Africa and Asia, more CO is detected than for South America and Australia (we disregard Russia and Alaska here due to the small correlation coefficients). This can have a variety of reasons, such as different types of burning materials, different fire types (hot blazing fire or smoldering), and weather conditions. Also the boxes of the selected areas need to be taken into account: Small areas are more sensitive to fire emissions, because the amount of fire counts per $\mathrm{km}^{2}$ is larger. A small region will, however, be more susceptible to the influence of wind, which can blow "clean" air into the region and fire-emitted trace gases $\left(\mathrm{CO}, \mathrm{NO}_{2}\right)$ out of it. The possible influence of clouds can be discarded, because the measurements presented here were cloud-filtered. An effect of cloud filtering on the monthly average can also be rejected, at least for $\mathrm{NO}_{2} \mathrm{TVCD}$ and aerosol index, since no significant difference was found when the cloud filter was changed from $5 \%$ to $30 \%$ (or even $100 \%$ for the aerosol index).

Fig 3(b) summarizes the results shown in detail in Fig. 2. The measured trace gas VCDs (both $\mathrm{CO}$ and $\mathrm{NO}_{2}$ ) show reasonable to good correlation with fire counts, aside from the most northern regions Russia and Alaska. The modeled CO VCD shows good agreement with measured values in most regions except Africa, as discussed above. Anti correlation of ECHAM5/MESSy and the fire counts for Alaska and Russia is due to the fact, that there are no or not many fire counts, but only a climatological seasonal background cycle. The correlation between SCIAMACHY and MOPITT is good, but not perfect. Further studies are required to find the reasons for this.

\section{CONCLUSIONS AND OUTLOOK}

We present time series and correlation studies of fire counts, CO VCD from SCIAMACHY, MOPITT, and ECHAM5/MESSy, $\mathrm{NO}_{2}$ TVCD and aerosol index from SCIAMACHY for selected regions with high biomass burning activity. For many regions we found the time series of all satellite measured $\mathrm{CO}, \mathrm{NO}_{2}$ and aerosol correlated quite well with ATSR fire counts. We also found CO retrieved from SCIAMACHY is in good agreement with MOPITT CO except for the systematic offset. However, for high latitudes the correlation is not good due to high solar zenith angle.

Somewhat surprisingly, the measurements of CO correlated much better with fire counts than the model data. The comparison with model data revealed some differences particularly over Africa which requires further investigation. It seems that either the biomass burning emissions which were based on the year 2000 or the interplay between convection and fire occurrence leads to differences between the seasonal cycles of the fire statistics and the simulated temporal evolution of the total CO column. Interestingly, the correlation between simulated $\mathrm{CO}$ and fire counts is relatively high in the tropics over South America, where the same mechanisms can be expected to distribute the biomass burning emissions as over Africa. The results of higher northern latitudes are difficult to compare directly to the data from 2004/2005 due to the fact that they largely depend on the strong interannual variability of the occurrence of biomass burning. For the year 2000 they are largely driven by the background seasonal cycle of $\mathrm{CO}$ rather than biomass burning or other sources. Unfortunately, no measurements are available for the particular period of 2000 , thus the simulations will be repeated with updated emissions for the year 2004/2005 to allow a quantitative comparison between the model and the observations and eventually with a higher model resolution.

The detailed comparison of measured $\mathrm{CO}$ with model data will be done in the future which should help improving models. In addition, we plan to compare the satellite observations of $\mathrm{CO}$ also to other trace gases like $\mathrm{HCHO}^{[21]}$ and 
aerosol index measured from satellite instruments for longer time series which should help improving our understanding the correlations between fire counts and emitted CO.

\section{ACKNOWLEDGEMENTS}

We would like to thank ESA (European Space Agency) and the DLR (Deutsches Zentrum Fur Luft- und Raumfahrt) for providing us with the L1b SCIAMACHY data files. Also, ESA provide the active fire counts from the Along-Track Scanning Radiometer (ATSR) sensor on board the ERS-2 satellite which could be downloaded from http://dup.esrin.esa.it/ionia/projects/projectsALPHA.asp.

We thank the TEMIS project for providing us with FRESCO+ data. The data were downloaded from: http:/www.temis.nl/.

We thank Space Science Division of the Canadian Space Agency for providing Measurements Of Pollution In The Troposphere (MOPITT) data. The data were downloaded from: http://eosweb.larc.nasa.gov/PRODOCS/mopitt/.

\section{REFERENCES}

[1] Crutzen, P.J. et al, A. "Biomass burning in the Tropics: Impact on atmospheric chemistry and biogeochemical cycles", Science, 250, 1669-1678, 1990.

[2] Thompson, A. M., et al., Ozone over southern Africa during SAFARI-92/TRACE A, J. Geophys. Res. 101(D19) 23,794-23,808, 1996.

[3] Langmann, B. et al. "Indonesia smoke aerosols from peat fires and the contribution from volcanic sulfur emissions, "Geophys, Res. Lett. 30 (11), 1547, doi: 10.1029/2002GL016646, 2003.

[4] A. M. S. Gloudemans et al. "The impact of SCIAMACHY near-infrared instrument calibration on $\mathrm{CH}_{4}$ and $\mathrm{CO}$ total columns." Atmos. Chen. Phys., 5, 1269-2383, 2005

[5] C. Frankenberg et al. "Retrieval of CO from SCIAMACHY onboard ENVISAT: detection of strongly polluted areas and seasonal patterns in global CO abundances. " Atmos. Chem. Phy., 5, 1639-1644, 2005.

[6] A. T. J. de Laat, "Quantitative analysis of SCIAMACHY carbon monoxide total column measurements. " GEOPHYSICAL RESEARCH LETTERS, VOL. 33, L07807, doi: 10.1029/2005GL025530, 2006.

[7] Torres, O. et al, " Derivation of aerosol properties from satellite measurements of backscattered ultraviolet radiation: Theoretical basis, " J. Geophys. Res. 103, 17099-17110, 1998.

[8] Beirle, S., Estimating source strengths and lifetime of Nitrogen Oxides from satellite data. PhD Thesis, University of Heidelberg, 2004. http://archiv.ub.uni-heidelberg.de/volltextserver/volltexte/2005/5225/pdf/diss_komplett.pdf//

[9] Jane Liu, et al. "Satellite mapping of CO emission from forest fires in Northwest America using MOPITT measurements." Remote sensing of Environment 95,502-516, 2005.

[10] N. Fournier, P. Stammes. "Improving cloud information over deserts from SCIAMACHY O2 A-band." Atmos. Chem. Phys. Discuss., 5, 6013-6039, 2005

[11] Bovensmann et al. "SCIMACHY mission objectives and measurement modes, " J. Atmos. Sci., 56, 127-150, 1999.

[12] C. Frankenberg et al. " Iterative maximum a posteriori (IMAP)-DOAS for retrieval of strongly absorbing trace gases: Model studies for $\mathrm{CH} 4$ and $\mathrm{CO} 2$ retrieval from near infrared spectra of SCIAMACHY onboard ENVISAT. " Atmos. Chem. Phy.,5, 922,2005

[13] Liwen Pan et al. "Retrieval of tropospheric carbon monoxide for the MOPITT experiment." J. Geophys. Res, 103, D24, 32277-32290, 1998.

[14] Arino, O. et al, J. "The 1993 Africa fire map, Int. J. Remote Sens., 19, 2019-2023, 1998.

[15] Penning de Vries, M.J.M. et al, " Cloud corrections for UV absorbing and scattering aerosol indices: A step on the way to quantitative aerosol information from cloudy scenes, "submitted, 2008.

[16] Tilstra, L.G. et al. "SCIAMACHY's Absorbing Aerosol Index and the consequences of instrument degradation", Proc. ACVE-3, 2007.

[17] Beirle, S. et al. "Highly resolved global distribution of tropospheric $\mathrm{NO}_{2}$ using GOME narrow swath mode data," Atmos. Chem. Phys., 4, 1913-1924, 2004. 
[18] T. Wagner et al. "Comparison of box-air-mass-factors and radiances for Multipe-Axis Differential Optical Absorption Spectroscopy (MAX-DOAS) geometries calculated from different UV/Visible radiative transfer models." Atmos. Chem. Phys., 7, 1809-1822, 2007.

[19] Jöckel, P. et al. "Evaluation of the atmospheric chemistry GCM ECHAM5/MESSy: Consistent simulation of ozone in the stratosphere and troposphere", Atmos. Chem. Phys., 6, 5067-5104, 2006.

[20] van Aardenne, J., Dentener, F., Olivier, J., Peters, J., and Ganzeveld, L. "The EDGAR3.2 Fast Track 2000 data set (32FT2000) ", www.mnp.nl/edgar/model/v32ft2000edgar/docv32ft2000, Joint Research Center, Institute for Environment and Sustainability (JRC-IES), Climate Change Unit, TP280, 21020 Ispra, Italy, 2005.

[21] Marbach. T. et al. "Biomass burning emissions from satellite observations: synergistic use of formaldehyde $(\mathrm{HCHO})$, fire counts and surface temperature, " submitted to SPIE Optics. 